\title{
Novel mechanisms for the metabolic control of puberty: implications for pubertal alterations in early-onset obesity and malnutrition
}

\author{
M J Vazquez1,2,3,4, I Velasco1,2 and M Tena-Sempere1,2,3,4,5 \\ ${ }^{1}$ Instituto Maimónides de Investigación Biomédica de Cordoba (IMIBIC), Cordoba, Spain \\ 2Department of Cell Biology, Physiology and Immunology, University of Cordoba, Cordoba, Spain \\ ${ }^{3}$ Hospital Universitario Reina Sofia, Cordoba, Spain \\ ${ }^{4}$ CIBER Fisiopatología de la Obesidad y Nutrición, Instituto de Salud Carlos III, Cordoba, Spain \\ 5FiDiPro Program, Department of Physiology, University of Turku, Turku, Finland
}

Correspondence should be addressed to M J Vazquez or M Tena-Sempere: bc2vavim@uco.es or fi1tesem@uco.es

\begin{abstract}
Puberty is driven by sophisticated neuroendocrine networks that timely activate the brain centers governing the reproductive axis. The timing of puberty is genetically determined; yet, puberty is also sensitive to numerous internal and external cues, among which metabolic/nutritional signals are especially prominent. Compelling epidemiological evidence suggests that alterations of the age of puberty are becoming more frequent; the underlying mechanisms remain largely unknown, but the escalating prevalence of obesity and other metabolic/feeding disorders is possibly a major contributing factor. This phenomenon may have clinical implications, since alterations in pubertal timing have been associated to adverse health outcomes, including higher risk of earlier all-cause mortality. This urges for a better understanding of the neurohormonal basis of normal puberty and its deviations. Compelling evidence has recently documented the master role of hypothalamic neurons producing kisspeptins, encoded by Kiss1, in the neuroendocrine pathways controlling puberty. Kiss 1 neurons seemingly participate in transmitting the regulatory actions of metabolic cues on pubertal maturation. Key cellular metabolic sensors, as the mammalian target of rapamycin (mTOR), AMP-activated protein kinase (AMPK) and the fuel-sensing deacetylase, SIRT1, have been recently shown to participate also in the metabolic modulation of puberty. Recently, we have documented that AMPK and SIRT1 operate as major molecular effectors for the metabolic control of Kiss 1 neurons and, thereby, puberty onset. Alterations of these molecular pathways may contribute to the perturbation of pubertal timing linked to conditions of metabolic stress in humans, such as subnutrition or obesity and might become druggable targets for better management of pubertal disorders.
\end{abstract}
Key Words
- puberty
- Kiss1
- kisspeptins
- $\mathrm{GnRH}$
- NKB
- mTOR
- AMPK
sirtuins
- obesity
- undernutrition
- environmental cues

\section{The neurobiological basis of puberty in mammals}

Puberty is a complex maturational phenomenon that drives the individual from an immature to a fully mature stage, when the capacity to reproduce is achieved.
While the multifaceted nature of puberty involves a variety of developmental changes, from psychological to somatic, a hallmark of puberty is the complete activation 
of the gonadal axis (Avendano et al. 2017). This is the result of the sequential awakening of the different elements of the so-called hypothalamic-pituitary-gonadal (HPG) axis. The major hierarchical element of this neurohormonal axis is the decapeptide, gonadotropin-releasing hormone (GnRH), which is produced by a discrete population of neurons in the basal forebrain, whose neurosecretory activity becomes fully activated at the time of puberty. GnRH is released in a pulsatile manner into the hypothalamic-pituitary portal vasculature, to reach the anterior pituitary, where it elicits the synthesis and secretion of both gonadotropins, LH and FSH. In turn, gonadotropins act on specific cell types of the gonads, promoting their trophic maturation, the production of gametes and the release of sex steroids and peptides (TenaSempere \& Huhtaniemi 2003).

The dynamic functioning of the HPG axis is primarily controlled by auto-regulatory feedback loops, whereby gonadal hormones operate at the upper levels of the axis to modulate, via negative and positive loops (the latter, only operative in females), the functioning of this system (Herbison 2016). In adulthood, the negative feedback of sex steroids is a major contributor for the tonic control of gonadotropin secretion in both sexes, while the positive feedback actions of estrogens and progestogens, specifically in females, are essential drivers of the preovulatory surge of gonadotropins, mandatory for ovulation. Of note, the dynamic interplay between the hormonal components of the HPG axis experiences substantial modifications during prenatal and postnatal development (Tena-Sempere \& Huhtaniemi 2003), with important changes in the sensitivity to the feedback effects of gonadal steroids being detected during (although probably not being causative of) the pubertal transition.

While activation of GnRH neurons is a wellrecognized key event in pubertal activation, the mechanisms whereby this activation is achieved remain partially unfolded. Despite evidence for intrinsic oscillatory activity of GnRH neurons, the capacity of this relatively scarce neuronal population, which is scattered in the preoptic hypothalamic area, to coordinately release GnRH in discrete pulses seemingly relies on the activity of a network of afferents that form the so-called GnRH pulse generator (Knobil 1980). This system integrates diverse excitatory and inhibitory inputs, from neural and non-neural sources (Maeda et al. 2010, Ojeda et al. 2010, Pinilla et al. 2012, Prevot et al. 2018), which are able to shape the pulsatile secretion of GnRH and adjust this secretory pattern to different physiological (or eventually, pathological) scenarios.
The nature and major components of such pulse generators have been the subject of active investigation; yet, full disclosure of the elements involved is still pending. The heightening of the neuro-secretory activity of GnRH neurons, which is observed during the onset of puberty (Lomniczi \& Ojeda 2016), is thought to be the result of a switch in the balance between excitatory and inhibitory inputs within and/or projecting to the $\mathrm{GnRH}$ pulse generator. In fact, it is assumed that the concurrent increase in excitatory inputs and decrease of inhibitory signals projecting to GnRH neurons is mandatory for their full pubertal activation (Lomniczi et al. 2015). In this context, compelling experimental evidence has identified a number of stimulatory signals, from glutamate to kisspeptins, capable to potently stimulate GnRH neurons during puberty, therefore suggesting a dominant role of excitatory inputs in driving puberty onset (Avendano et al. 2017). Nonetheless, recent molecular data have also pointed out the importance of the timely eviction of inhibitory signals, such as makorin-3 or specific epigenetic marks, to allow the complete activation of these pubertydriving systems (Lomniczi \& Ojeda 2016, Avendano et al. 2017). All in all, the current view is that, rather than the result of a specific or unique trigger, puberty onset is driven by the dynamic interplay of a number of stimulatory and inhibitory factors, ultimately impinging on the GnRH pulse generator, which is capable to precisely transmit the modulatory influence of multiple pubertal regulators, including metabolic signals.

\section{The fundamental roles of kisspeptins in timing puberty onset in mammals}

Among the numerous central transmitters involved in pubertal control, kisspeptins, a family of peptides encoded by the Kiss 1 gene, have been recognized in recent years as fundamental gatekeepers of puberty onset (Pinilla et al. 2012). Seminal findings in late 2003 conclusively documented that genetic inactivation of Gpr54, the canonical receptor for kisspeptins, causes lack of pubertal maturation and hypogonadotropic hypogonadism both in humans and mice (de Roux et al. 2003, Seminara et al. 2003); findings that were later confirmed also for Kiss1 inactivation (d'Anglemont de Tassigny et al. 2007, Topaloglu et al. 2012). While a detailed recapitulation of the major features of kisspeptins as master regulators of the reproductive axis exceeds the scope of this review and can be found elsewhere (Pinilla et al. 2012, Manfredi-Lozano et al. 2018), it is important to stress that compelling genetic 
and pharmacological evidence attests the relevance of the Kiss1 system not only in early maturational events (e.g., brain sexual differentiation), essential for proper functioning of the reproductive axis later in life, but also in the activational phenomena leading to the onset of puberty. This is epitomized by data from experimental studies manipulating hypothalamic kisspeptin signaling in a timed manner during postnatal/pubertal maturation, which documented that blockade of kisspeptin receptors with specific antagonists delayed puberty onset in female rats (Pineda et al. 2010) and blocked GnRH secretion in pre/peripubertal female monkeys (Guerriero et al. 2012), while acute or chronic administration of kisspeptins, via different routes, not only stimulated gonadotropin release via GnRH-dependent mechanisms (Avendano et al. 2017), but was also sufficient to induce different phenotypic marks of puberty in female rats (Navarro et al. 2004b).

Interestingly, the Kiss1 system undergoes substantial developmental changes during the pubertal transition, which are characterized by a significantly elevation of both Kiss 1 mRNA expression and kisspeptin content at the hypothalamus (Navarro et al. 2004a, Shahab et al. 2005), together with an increase in the number of kisspeptinexpressing neurons, as well as their projections to $\mathrm{GnRH}$ neurons (Clarkson \& Herbison 2006, Bentsen et al. 2010). In addition, during puberty, the sensitivity to the releasing actions of kisspeptins on GnRH/LH secretion increases; a phenomenon that is coupled to some resistance to desensitization to continuous kisspeptin stimulation, at least in rodents (Castellano et al. 2006, Roa et al. 2008). All these features set a state of maximal activation of kisspeptin signaling in the brain centers governing the reproductive axis during the pubertal transition.

Two major populations of Kiss1 neurons have been described in the hypothalamus; a feature that has been well documented in rodents but also reported in other mammalian species. Notably, these two sets of neurons are differentially regulated, display a sexually different distribution and are thought to play different roles in the control of key aspects of HPG axis (Pinilla et al. 2012). The most prominent of these two Kiss1 neuronal populations is located in arcuate nucleus (ARC) or infundibular region in humans; this set of Kiss1 neurons has been implicated in negative feedback control and the pulsatile secretion of gonadotropins in both sexes. The second Kiss1 population is sited in the rostral hypothalamic area, specifically at the anteroventral periventricular nucleus (AVPV) in rodents, or the preoptic area (POA) in non-rodents; this neuronal population is present mainly in females, it being especially abundant in rodents and is responsible for the positive feedback control and the preovulatory surge of gonadotropins (Pinilla et al. 2012).

The ARC and AVPV populations of Kiss1 neurons not only respond differently to sex steroid and control different aspects (pulsatile vs surge mode) of the secretion of gonadotropins. In addition, they also have a differential neuropeptide landscape, with different co-transmitters being expressed in the two neuronal sets. This is especially well-defined in ARC Kiss1 neurons, which, unlike AVPV neurons, are known to produce neurokinin B (NKB), a prominent member of the tachykinin family, and Dynorphin (Dyn), along with their functional receptors. Actually, because of the co-expression of Kiss1, NKB and Dyn, this ARC population was named KNDy neurons (Lehman et al. 2010). Admittedly, the specific roles of such co-transmitters in the control of puberty are not completely understood. Yet, various studies, conducted mostly in rodents, have suggested a role of NKB and Dyn in the modulation of pubertal timing (Gill et al. 2012, Navarro et al. 2012), likely due to their capacity to precise and reciprocally modulate kisspeptin release (Navarro et al. 2009). In line with this putative function, inactivating mutations of the genes encoding NKB or its receptor (NK3R) are associated to the absence of puberty in humans (Topaloglu et al. 2009), whereas blockade of Dyn signaling, by administration of an antagonist of its receptor (kappa-opioid receptor, KOR), leads to the advancement of puberty (Nakahara et al. 2013). Thus, while NKB is considered to stimulate Kiss1 neurons, and therefore, GnRH/gonadotropin secretion, Dyn opposes to such effect (Navarro 2013). All in all, ARC Kiss1 neurons appear to be equipped with a basic oscillatory set, in which NKB and Dyn stimulate or inhibit, respectively, kisspeptin output to GnRH neurons, as a major component for the full activation of GnRH neurosecretory activity during puberty and its dynamic regulation later in life. In this function, other tachykinins, such as Substance P/NK1R, appear to cooperate with ARC kisspeptin signaling in the precise timing of puberty (Simavli et al. 2015). Notably, ARC Kiss1 neurons appear to directly or indirectly sense and integrate multiple inputs, including nutritional, metabolic and environmental cues, to precisely regulate GnRH function and thereby the timing of puberty (Avendano et al. 2017, Manfredi-Lozano et al. 2018).

The roles of the rostral population of Kiss1 neurons in the control of puberty onset have been also investigated, although its physiological relevance may vary according to the species. In any event, AVPV Kiss1 neurons increase in number and projections to GnRH neurons during the pubertal transition in mice (Clarkson \& Herbison 2006), 
and partial suppression of kisspeptin at this hypothalamic site caused a delay on phenotypic marks of puberty onset in female rats (Adekunbi et al. 2017). Whether AVPV Kiss1 neurons have a role in transmitting the modulatory effects of nutritional/metabolic cues on pubertal timing is yet to be defined. On the other hand, a third population of Kiss1 neurons has been described in the amygdala in rodents. The function of this set of Kiss1 neurons remains largely unknown (Pineda et al. 2017), but has been the subject of active investigation recently. Thus, amygdala Kiss1 expression is negligible in juvenile mice, but increases substantially during the late pubertal period, coinciding with (and being probably driven by) the rise of circulating sex steroids (Stephens et al. 2016). The physiological role of such activation of Kiss1 expression in the amygdala during late puberty is unknown. However, it has been reported that blockade of kisspeptin signaling in the postero-dorsal medial amygdala (MePD) of female rats, by selective infusion of a specific antagonist during the juvenile period, delayed puberty onset (Adekunbi et al. 2017). Interestingly, this set of MePD Kiss1 neurons is sensitive to metabolic cues, so that maternal obesity increased Kiss1 expression at the MePD in prepubertal male and female rats, but decreased it in adulthood. In addition, chemo-genetic (DREADD-mediated) activation of MePD Kiss1 neurons have been recently reported to increase gonadotropin secretion in adult mice, while NKB signaling in the MePD also stimulates LH secretion, albeit in a Kiss1-independent manner (Fergani et al. 2018). Altogether, these data suggest that kisspeptin signaling at or steaming from the amygdala may have a role in the control of puberty and the gonadotropic axis, although its relative importance (vs ARC and AVPV neurons) and eventual roles in conveying the regulatory actions of metabolic and nutritional signals on pubertal timing are yet to be clarified.

\section{Metabolic control of puberty in mammals: key hormonal and neuropeptide pathways}

Among its numerous modulators, metabolic and nutritional cues are fundamental modifiers of the timing of puberty. Reproduction is an energy-consuming process, especially in females, and therefore, acquisition and maintenance of reproductive capacity are tightly bound to the state of body energy reserves. Accordingly, conditions of persistent deregulation of energy and metabolic homeostasis are correlated with alterations in puberty onset. Thus, while chronic energy deficiency (e.g. in malnutrition or anorexia) is associated with delayed puberty, excess of body energy stores (e.g. in obesity) is commonly been linked to earlier onset of puberty (Hill \& Elias 2018, Manfredi-Lozano et al. 2018). Moreover, in physiological conditions, a minimum of body fat mass needs to be achieved in order to attain the reproductive capacity. While the level of fat reserves required to undergo puberty displays considerable interindividual variability, this concept laid the foundations of the classical critical fat mass hypothesis (Frisch \& Revelle 1970), formulated in 1960s and 70s by Frisch and coworkers, which set the scene for the identification of the actual factors responsible for such a tight coupling between body energy/metabolic status and puberty onset.

The precise pathways whereby metabolic information is transmitted to the brain centers governing the reproductive axis are not completely disclosed, but certainly involve numerous peripheral and central signals. Among the metabolic cues affecting puberty onset, leptin is a paradigmatic example, which plays a fundamental role as physiological link between fat stores and pubertal timing (Ahima et al. 2000, Castellano \& Tena-Sempere 2016). The physiological features of leptin, including its role as major reproductive modulator, have been extensively revised elsewhere (Ahima et al. 2000, Louis \& Myers 2007, Castellano \& Tena-Sempere 2016, Hill \& Elias 2018). For the purpose of this review, it is important to stress that, as adipokine being secreted in proportion of the body fat stores, leptin operates as pleotropic neuroendocrine integrator, linking the state of body energy reserves to numerous body functions, including not only weight homeostasis but also puberty and fertility. Indeed, conditions of leptin signaling deficiency in humans and experimental animals are associated to delay or absence of puberty and compromised fertility (Farooqi \& O'Rahilly 2014, Vazquez et al. 2015). Despite the initial evidence suggesting a role of leptin as potential trigger of puberty, the current notion is that leptin plays a fundamental role as a permissive signal for puberty to occur, as illustrated by the fact that leptin replacement in leptin-deficient humans and rodents rescues pubertal development, without markedly advancing it, while leptin administration is capable to restore the onset of puberty in food-restricted rodents (Manfredi-Lozano et al. 2018). Likewise, leptin treatment to women with hypothalamic amenorrhea, due to low weight or strenuous exercise, was sufficient to re-awake the functioning of the reproductive axis, with recovery of menstrual cycles or preovulatory follicular maturation (Welt et al. 2004). Hence, in keeping with the critical fat mass hypothesis, a minimum level of 
leptin appears to be necessary to complete full pubertal maturation or for regaining reproductive competence in conditions of metabolic stress.

Considerable attention has been paid to unveil the mechanism whereby leptin modulates puberty onset and the functioning of the HPG axis. Compelling evidence suggests that leptin-mediated actions are conducted by different sets of neurons, mainly at the hypothalamic level, capable to integrate metabolic and nutritional signals, and to transmit them onto GnRH neurons. Indeed, despite their pivotal position as major output pathway of the reproductive brain, GnRH neurons seem to lack functional leptin receptors, as documented in rodents and primates (Finn et al. 1998, Quennell et al. 2009), suggesting the implication of intermediate pathways for mediating leptin effects. Accordingly, different neuropeptides and hypothalamic circuits have been suggested to convey leptin actions onto GnRH neurons (Elias 2012, ManfrediLozano et al. 2018).

Given their fundamental role in the control of different facets of reproductive function, Kiss1 neurons have been extensively investigated as putative pathway transmitting metabolic information, and particularly leptin actions, to GnRH neurons. Conclusive evidence has documented that the Kiss1 system is highly sensitive to changes in metabolic and nutritional cues, as well as to alterations in leptin levels or signaling, suggesting that the state of body energy reserves and leptin levels influence the reproductive axis, at least partially, via modulation of Kiss1 neurons (Navarro \& Tena-Sempere 2011). Thus, conditions of metabolic distress known to perturb puberty and/or gonadotropin secretion, such as chronic undernutrition or early-onset overfeeding, have a profound influence on the hypothalamic expression of Kiss1/kisspeptin. For instance, conditions of food deprivation and leptin deficiency are associated to decreased levels of hypothalamic Kiss1 expression or kisspeptin content in various species (Castellano \& Tena-Sempere 2016), whereas exogenous administration of kisspeptin is able to normalize the onset of puberty or to rescue the functionality of the HPG axis in those conditions (Castellano et al. 2005). Of note, excess of adiposity appear to have a biphasic impact on the Kiss1 system: while overfeeding during postnatal/peripubertal period causes an increase of hypothalamic Kiss1 expression and advances puberty onset, persistent energy excess and obesity in adulthood is associated to suppression of Kiss1 expression and reproductive dysfunction in rodents (Castellano et al. 2011, Quennell et al. 2011, SanchezGarrido et al. 2014).

(C) 2019 Society for Endocrinology Published by Bioscientifica Ltd. Printed in Great Britain
While the different populations of Kiss1 neurons (ARC, AVPV and MePD) have been shown to be sensitive to metabolic cues, Kiss1 neurons in the ARC appear to have a more prominent role in the metabolic control of the HPG axis and puberty onset. Initial studies demonstrated that a subset of ARC Kiss1 neurons express leptin receptors, in rodents and sheep (Smith et al. 2006, Backholer et al. 2010), whereas ARC Kiss1 neurons are activated by leptin via transient receptor potential cation (TRPC) channels in guinea pigs (Qiu et al. 2011). In addition, reduced or null leptin levels have been associated with the inhibition of Kiss1 expression, mainly in the ARC, whereas leptin administration increased the hypothalamic expression of Kiss1 gene in different models of severe metabolic stress, such as leptin-deficient mice or diabetic rats, as well as in neuronal cell lines (Manfredi-Lozano et al. 2018). Notably, while postnatal overfeeding, causing earlier puberty onset, resulted in higher levels of leptin, hypothalamic Kiss1 expression and numbers of kisspeptin fibers, in pubertal female rats, postnatal underfeeding, which is associated to delayed vaginal opening, resulted in lower in leptin and Kiss1 mRNA levels, together with a decrease in the number of kisspeptin-positive neurons in the ARC (Castellano et al. 2011). Altogether, these findings suggest a tight interplay between leptin and Kiss1 neurons, preferentially (albeit not exclusively) in the ARC, for the metabolic regulation of puberty.

Notwithstanding the above experimental evidence, some studies have provided evidence for the lack of direct effects of leptin on Kiss1 neurons, therefore suggesting an indirect (or even independent) mode of action. Thus, congenital elimination of leptin receptors from Kiss1 neurons was compatible with normal pubertal maturation and reproductive capacity in female mice (Donato et al. 2011b); yet, the possibility of some degree of developmental compensation cannot be ruled out in this model. In addition, neuroanatomical studies in rodents and sheep, mapping functional leptin receptors in different brain areas, failed to detect significant amounts of leptin receptors in GnRH or Kiss1 neurons (Cravo et al. 2011, Louis et al. 2011), with the exception of a modest subset of Kiss1 cells in the ARC (Louis et al. 2011). Yet, other studies have indicated that leptin receptors arise in Kiss1 neurons after puberty, suggesting a role for leptin in the direct control of Kiss1 neurons only after pubertal maturation (Cravo et al. 2013). In any event, the fact that most of the studies addressing the roles of leptin actions on the Kiss1 system have been conducted at periods other than puberty hampers extrapolation of these findings to the particular roles of leptin in the pubertal modulation 
of Kiss1 neurons. Nonetheless, identification of leptin receptor-expressing cells in the close vicinity of ARC and AVPV Kiss1 neurons further attests that leptin actions on Kiss1 neurons may be predominantly indirect.

In this context, compelling evidence has documented that the ventral premammilary nucleus (PMV) of the hypothalamus is a relevant site for leptin actions in the modulation of the reproductive axis. Indeed, part of PMV cells expresses leptin receptors and projects to GnRH and Kiss1 neuron (Donato et al. 2011b). Activation of leptin signaling in the PMV is sufficient to restore pubertal development and fertility in leptin-deficient mice (Donato et al. 2011a,b), whereas specific lesions of the PMV caused alterations of Kiss 1 neurons and delayed puberty (Donato et al. 2013). The nature of these PVM neurons relying on leptin actions remains enigmatic, but recent reports suggest that they may include a set of PACAP neurons, which project to ARC and AVPV Kiss1 neurons and whose deletion caused delayed puberty and perturbed reproductive function in female mice (Ross et al. 2018). In addition, other populations of leptin-responsive neurons outside the PVN, such as GABAergic or NO-producing neurons, the latter sited in the POA, have been shown to contribute in mediating the actions of leptin on puberty onset and the HPG axis, via modulation of Kiss1 neurons (Bellefontaine et al. 2014, Martin et al. 2014).

Finally, very recent genetic and functional genomic studies have revealed a major role of semaphorin 3 (SEMA3) signaling in the development of the hypothalamic melanocortin circuits controlling energy homeostasis, whose disruption leads to obesity (van der Klaauw et al. 2019). Notably, SEMA3 ligands and receptors had been previously linked not only to the development of the GnRH system, as reflected by the fact that mice and humans with mutations in SEMA3 genes suffer defective GnRH neuronal migration, impuberism and central hypogonadism (Hanchate et al. 2012, Marcos et al. 2017), but also to the dynamic regulation of GnRH release by sex steroids (Giacobini et al. 2014). Hence, the potential interplay between SEMA3 signaling, the melanocortin pathway and GnRH neurons in the metabolic control of puberty warrants specific investigation. In addition, since melanocortin signaling and Kiss1 neurons have been shown to interplay for the regulation of puberty (ManfrediLozano et al. 2016), a putative role of kisspeptins in such a novel circuitry cannot be discarded. In the same vein, whether miRNA regulatory pathways, with relevant roles in the development of feeding-controlling circuits in the ARC (Croizier et al. 2018) and the functional maturation of GnRH neurons (Messina et al. 2016), may participate in the metabolic control of puberty is currently being investigated in our laboratory.

\section{Cellular energy sensors and the metabolic control of puberty: roles of $\mathrm{MTOR}$ and AMPK}

In an attempt to disclose the molecular mechanisms whereby nutritional and metabolic cues modulate puberty onset, experimental studies from our group have recently addressed the putative roles of cellular energy sensors, such as the mammalian (or mechanistic) target of rapamycin (mTOR) and the AMP-activated protein kinase (AMPK), in the central control of the HPG axis and Kiss1 neurons. These analyses were fueled by previous studies highlighting the function of MTOR and AMPK in specific hypothalamic populations in the control of whole-body energy homeostasis, by modulating food intake and/or thermogenesis (Cota et al. 2006, Roa \& Tena-Sempere 2010, Lopez et al. 2016). In addition to these critical functions, the data reviewed in this section illustrate a relevant role of these two energy sensors as mediators for the metabolic control of puberty, acting at central levels to modulate key elements of the reproductive brain, such as Kiss1 neurons.

Our studies in this area were initially focused on mTOR. This is an evolutionarily conserved serine/ threonine protein kinase that acts as a cellular sensor of energy status and growth signals, thereby participating in the control of key cell functions, as cell proliferation, growth and metabolism. Contrary to AMPK, mTOR is activated in situations of energy excess to promote anabolic pathways, the inter-relationship between AMPK and mTOR being fundamental in the control of numerous cellular activities (Roa \& Tena-Sempere 2010, Lopez et al. 2016). At the hypothalamic level, the mTOR signaling pathway is thought to transmit and integrate information concerning nutrient availability (mainly, amino acids) and the hormonal milieu (such as ghrelin and leptin effects), and hence, is essential for maintenance of energy balance at the whole body level (Martins et al. 2012).

In this context, studies carried out in our group demonstrated that hypothalamic mTOR plays an important role in the metabolic control of puberty, mediating at least part of the permissive effects of leptin on pubertal onset (Roa et al. 2009). Thus, chronic central blockade of $\mathrm{mTOR}$ in peripubertal female rats, by repeated intracerebral injection of rapamycin, delayed pubertal maturation, as evidenced by lower circulating levels of LH and estradiol, decreased ovarian and uterus weights 
and deferred vaginal opening, as external sign of puberty onset. In addition, persistent inhibition of mTOR at central levels prevented also the permissive effects of leptin in terms of rescue of puberty onset in a model of leptin deficiency due to chronic subnutrition. On the other hand, central activation of mTOR, by intracerebral administration of L-leucine, partially recovered the low gonadotropin levels caused by subnutrition. The mechanisms through which modulation of mTOR is affecting puberty seemingly involve the regulation of Kiss1 neurons, as mTOR inactivation significantly suppressed Kiss1 expression, mainly in the ARC, without affecting LH responsiveness to exogenous kisspeptin (Roa et al. 2009); the latter suggests that the downstream targets of kisspeptins remained operative despite mTOR blockade. Overall, these observations convincingly suggest the existence of a leptin-mTOR-kisspeptin pathway that plays a key role in the metabolic control of puberty (Roa \& TenaSempere 2010). Yet, the neuroanatomical components of such a circuitry remain unfolded and might involve an indirect modulation of Kiss 1 expression by mTOR, acting within intermediary neuronal pathways. This is suggested by the fact that pS6, a fundamental downstream target of mTOR, is apparently not expressed in Kiss1 neurons (Quennell et al. 2011).

More recent studies from our team have unveiled also a key role of AMPK in the metabolic regulation of puberty. AMPK, the major energy sensor at the cellular level, is a serine/threonine kinase with a catalytic $\alpha$ subunit, of which two isoforms, $\alpha 1$ and $\alpha 2$, exist. AMPK is activated in conditions of energy depletion to generate ATP and, therefore, re-establish the AMP:ATP ratio. As a result of such activation, catabolic (ATP-generating) pathways are increased, whereas anabolic (ATP-consuming) routes are inhibited (Canto et al. 2009). At the hypothalamic level, AMPK has been implicated in whole-body energy homeostasis mainly through the regulation of food intake and energy expenditure (Hardie et al. 2012, Lopez et al. 2016), acting as an integrative pathway to convey the modulatory actions on energy homeostasis of multiple hormonal regulators. As example, in specific hypothalamic nuclei, such as the ARC, AMPK is activated by the main orexigenic hormone (i.e. ghrelin), whereas is inhibited by leptin, as the most relevant anorectic factor (Martins et al. 2012). In addition, modulation of AMPK activity in the ventromedial hypothalamus ( $\mathrm{VMH}$ ) by a large array of regulators, from estrogens to thyroid hormones, plays a fundamental role in the central control of thermogenesis by the brown adipose tissue (Lopez et al. 2016).
In addition to its fundamental role in energy homeostasis, AMPK is also involved in a broad spectrum of metabolic and physiological processes, ranging from glucose/lipid metabolism to neuroendocrine control and oncogenesis (Hardie et al. 2012, Lopez et al. 2016). In this context, a putative function of hypothalamic AMPK in the metabolic control of reproduction in adulthood was initially suggested; as molecular sensor of conditions of energy distress, AMPK was proposed to remit nutritional and metabolic information to the reproductive brain (Roland \& Moenter 2011). These studies indirectly pointed also to a potential role of AMPK in the modulation of the Kiss1 system. Thus, hormonal or pharmacological activation of AMPK suppressed Kiss1 expression and GnRH secretion in the immortalized GnRH cell line, GT1-7 (Coyral-Castel et al. 2008, Wen et al. 2012), while central administration of an AMPK activator inhibited Kiss1 expression and disrupted estrous cyclicity in adult rodents (Coyral-Castel et al. 2008, Wen et al. 2012). Yet, the eventual role of AMPK signaling in Kiss1 neurons in the metabolic control of puberty was not initially explored.

In this context, recent studies from our group have thoroughly documented a novel neuroendocrine circuit linking conditions of negative energy balance and pubertal timing via the AMPK-Kiss1 pathway (Roa et al. 2018). Thus, chronic peripubertal subnutrition, which was associated to the expected delay in the age of vaginal opening, caused a significantly increase of hypothalamic p-AMPK levels in female rats. In turn, AMPK gain-of-function experiments, involving either central administration of the AMPK activator, AICAR or the ARC-specific virogenetic overexpression of a constitutively active form of AMPK (AMPK-CA), caused variable degrees of pubertal delay. Notably, the delay of puberty onset caused by AMPK activation was associated with a significant suppression of Kiss1 expression in the ARC, where kisspeptin and p-AMPK were found to be co-expressed in a subset of ARC Kiss1 neurons, therefore suggesting a direct link between AMPK signaling and Kiss1 in the ARC as pathway for mediating the modulatory effects of conditions of negative energy balance on puberty onset. This contention was further supported by functional genomic studies involving conditional ablation of $\alpha 1 \mathrm{AMPK}$ in Kiss 1 cells. These mice, named KAMKO (for Kiss1-specific AMPK knockout), failed to display major alterations in pubertal timing in conditions of feeding ad libitum, but were partially protected against the delay in pubertal maturation caused by chronic undernutrition. Altogether, these studies illustrate the fundamental role 
of hypothalamic AMPK signaling in the metabolic control of puberty, acting via repressive modulation of ARC Kiss1 neurons in conditions of negative energy balance (Roa et al. 2018).

Admittedly, the potential function of AMPK in the metabolic control of puberty and the reproductive axis might involve also actions at cell types, other than Kiss1 neurons, with relevant roles in the HPG axis. For instance, AMPK signaling in GnRH neurons has been linked to the impact of glucoprivation on the gonadotropic system (Roland \& Moenter 2011). In addition, non-neuronal actions of AMPK might be involved as well, since malnutrition-induced AMPK activation at ependymocytes of the lower brainstem contributes also to suppression of $\mathrm{GnRH} / \mathrm{LH}$ secretion in conditions of negative energy balance (Minabe et al. 2015). It must be noted, however, that the above studies were conducted in adulthood, and hence, extrapolation to potential puberty-regulatory mechanisms must be done with caution and requires experimental validation. In any event, a potential role of AMPK signaling in GnRH neurons in the precise control of puberty onset is suggested by our on-going functional genomic studies showing that female mice engineered to congenitally lack $\alpha 1 \mathrm{AMPK}$ in GnRH cells display earlier vaginal opening but deferred first ovulation (M J Vazquez, I Velasco and M Tena-Sempere, unpublished observations).

\section{Linking puberty and longevity? Emerging roles of Sirtuin-1 in the metabolic control of puberty}

In addition to AMPK and mTOR, sirtuins have emerged in the last decades as pleiotropic metabolic modulators. The sirtuin family is composed in mammals by seven members (SIRT1-7), of which SIRT1 is the most thoroughly studied and best characterized (Nogueiras et al. 2012). SIRT1, the mammalian ortholog of Sir2 in C. elegans, is a ubiquitously expressed ( $\left.\mathrm{NAD}^{+}\right)$-dependent class III deacetylase involved in a plethora of key functions including modulation of longevity and wealth-span, epigenetic regulation and metabolic homeostasis (Nogueiras et al. 2012, Giblin et al. 2014). SIRT1 acts as a genuine cellular energy sensor, as its deacetylase activity is dependent on the metabolic cofactor, $\mathrm{NAD}^{+}$, and related intermediates (NADH and nicotinamide), it being activated in conditions of energy deficit, such as caloric restriction and nutrient deprivation, which cause increased $\mathrm{NAD}^{+} / \mathrm{NADH}$ ratios (Nogueiras et al. 2012, Chang \& Guarente 2014). Among its known targets, histones are subjected to deacetylation by SIRT1, as key component of the epigenetic machinery.

In vivo studies, carried out in adult mice, have documented the expression of Sirt1 in different hypothalamic nuclei involved in neuro-vegetative control, such as the ARC, where its levels are modulated by nutrient availability, they being modestly increased after fasting (Ramadori et al. 2008). In addition, global, moderate overexpression of Sirt1 in mice revealed a protective role of SIRT1 against metabolic damage induced by chronic exposure to high-fat diet. Accordingly, SIRT1 has been proposed as a key modulator of body energy and metabolic homeostasis, although its predominant site of action (whether peripheral or central) remains partially unfolded. In any event, physiological and genetic studies involving brain activation or overexpression of this sirtuin strongly suggest a relevant role of central SIRT1 in the control of aging and as mediator of the beneficial effects of caloric restriction on lifespan in mice.

A potential role of SIRT1 in reproductive physiology was initially suspected based on the defective reproductive phenotype observed in Sirt1-null mice (McBurney et al. 2003). Since then, an as yet limited number of SIRT1 gain- and loss-of-function approaches have provided evidence of the putative involvement of this sirtuin in different aspects of reproduction, with a major focus on its participation in the control of gonadal physiology (Tatone et al. 2018). In this context, SIRT1 has been linked to the control of ovarian reserve and oocyte growth and maturation; the latter in cooperation with other sirtuins. In addition, SIRT1 has been found to modulate granulosa cells in the ovary, as well as spermatogenesis in the testis. As a consequence of these physiological roles, changes in SIRT1 activity have been involved and/or proposed as a therapeutic target for reproductive pathologies, such as endometriosis or polycystic ovary syndrome (Tatone et al. 2018). Regarding potential central actions of SIRT1 in the control of the reproductive axis, mice with congenital Sirt1 deficiency displayed central hypogonadism due to defective GnRH neuronal migration to the hypothalamus (Kolthur-Seetharam et al. 2009, Di Sante et al. 2015). Notwithstanding the above, whether central SIRT1 is implicated in the metabolic control of reproduction or may act as a linker between energy availability and the reproductive brain to modulate timing of puberty had not yet been addressed until recently.

In this context, in close collaboration with the Ojeda/ Lomniczi group, we have recently provided compelling evidence for a novel key epigenetic mechanism, involving SIRT1/Kiss1 signaling at the hypothalamus, by which 
nutritional cues modulate Kiss1 neurons in the ARC, affecting the precise timing of female puberty in rodents (Vazquez et al. 2018). Our findings demonstrated that the hypothalamic content of SIRT1 declines during postnatal/pubertal maturation, which is coincident with the well-characterized increase of Kiss1 expression during this developmental period. In addition, by using suitable preclinical models of pubertal alteration due to nutritional/metabolic manipulations, our data have shown that hypothalamic SIRT1 content is modulated by the nutritional status, as suggested by previous data in adult mice (Ramadori et al. 2008) and is negatively correlated to Kiss1 expression. Thus, in a rat model of precocious puberty induced by early-onset obesity (Sanchez-Garrido et al. 2013), we have documented a reduction in the hypothalamic levels of SIRT1 and a concomitant increase of Kiss 1 expression, whereas a model of chronic peripubertal undernutrition, which delayed puberty onset, presented an elevation of SIRT1 protein and reduced expression of Kiss1 at the hypothalamic level. This inverse relationship between SIRT1 and Kiss1 was mainly observed in ARC Kiss1 neurons, where SIRT1 is expressed in an energy-dependent fashion: SIRT1 content decreased in ARC Kiss1 neurons of obese rats, whereas it increased in Kiss1 neurons of the ARC of undernourished rats.

This inhibitory influence of central SIRT1 on Kiss1 transcription was corroborated by functional manipulation of SIRT1 levels/activity, using three different approaches: (i) pharmacological activation of central SIRT1 (by central infusion of the Sirt1 Activator, SA3); (ii) a transgenic model of moderate Sirt1-overexpression (SIRT1-Tg) and (iii) virogenetic ARC-specific overexpression of Sirt1 (AAVSIRT1) after stereotaxic delivery. In these studies, the increase of SIRT1 activity, as evidenced by decreased levels of acetylation marks of its target, Histone3 (H3K9/14ac), was associated to inverse changes of Kiss 1 expression in vivo and, therefore, to the expected delay of pubertal timing, in terms of deferred vaginal opening and first ovulation and decreased LH levels (Vazquez et al. 2018). In addition, by a combination of in vitro and in vivo studies, we have also disclosed the molecular underpinnings of the repressive actions of SIRT1 on Kiss1; our data identify SIRT1 as a fundamental epigenetic element to link nutritional status and pubertal timing acting mainly by regulation of Kiss1 transcription in the ARC. Thus, at a prepubertal stage, SIRT1 recruits the repressor, EED, a member of Polycomb group, to the Kiss1 promoter where, by inducing a repressive histone landscape, Kiss1 transcription is inhibited and pubertal progression is halted. In contrast, during pubertal activation, SIRT1 is timely evicted from the Kiss1 promoter to change the chromatin configuration, with an increase of the abundance of activating histone modifications (namely, H3K9ac and H4K16ac) and a reduction of the repressive histone marks (as H3K4me3), which result in enhanced Kiss1 transcription, as mandatory for puberty to occur. More relevant, conditions of energy excess, such as earlyonset obesity, accelerate these changes, whereas chronic energy deficit induces puberty delay by a protracted SIRT1-mediated repression of Kiss1 expression (Vazquez et al. 2018).

\section{Translational implications: mechanisms for perturbed puberty in obesity and malnutrition}

Deciphering the basic mechanisms for the control of puberty and its modulation by nutritional and metabolic cues poses not only physiological interest but also important translational implications. Epidemiological studies have surfaced worrying trends of changes in the timing of puberty in different countries. Such changes involve mainly an advancement of the age of puberty onset, that has been more consistently reported in girls, with earlier entry in thelarche or Tanner stage B2 of breast maturation, but that have been also documented by some series in pubertal boys (Aksglaede et al. 2009a,b, HermanGiddens et al. 2012, De Leonibus et al. 2014). Apart from their putative impact on the reproductive axis itself, changes in the age of puberty, not only advancement but also delay or absence, have been described to have a deleterious influence on different body functions, including somatic growth and psychological maturation, and, in fact, perturbed pubertal timing has been associated to diverse negative health outcomes, which include different types of cancer as well as higher risks of cardiometabolic (including hypertension and type-2 diabetes), gynecological-obstetric, cognitive, gastrointestinal and musculoskeletal disorders (Day et al. 2015), resulting in an overall reduction of the total life expectancy (Lakshman et al. 2009). All these epidemiological features urge for a better understanding of the basis of normal puberty and the pathophysiological mechanisms underlying its perturbations.

While the causes for higher incidence of earlier (or delayed) puberty remain unfolded, their rapid instauration (over one generation) argues in favor a major role of environmental cues, among which nutritional habits, 
and their corresponding endogenous metabolic and hormonal signals, appear to play a very relevant role. In fact, the escalating trends for changes in the age of puberty during the last two decades grossly coincide with the increasing frequency of metabolic disorders in childhood, of which early-onset obesity is the most common one, with an ever-growing prevalence that has been linked to earlier puberty onset. Nonetheless, feeding problems involving conditions of negative energy balance, such as anorexia nervosa, are also common among adolescents, therefore defining a wide range of conditions in which deranged metabolic signals may have a notable impact on pubertal maturation.
Our recent preclinical work on the role of metabolic and energy sensors may help to shed some light into the ultimate mechanisms whereby extreme conditions of body weight, from early-onset subnutrition to obesity, affect the neuroendocrine systems governing puberty onset. A schematic for the putative mode of action of these energy/metabolic sensing systems in conditions of persistent energy deficit or excess is depicted in Fig. 1. Thus, conditions of persistent negative energy balance linked to malnutrition, which are known to lower circulating leptin levels, would inhibit hypothalamic Kiss1/kisspeptin expression, as major mechanism for the suppression/ delay of puberty onset, by the reciprocal alteration of the

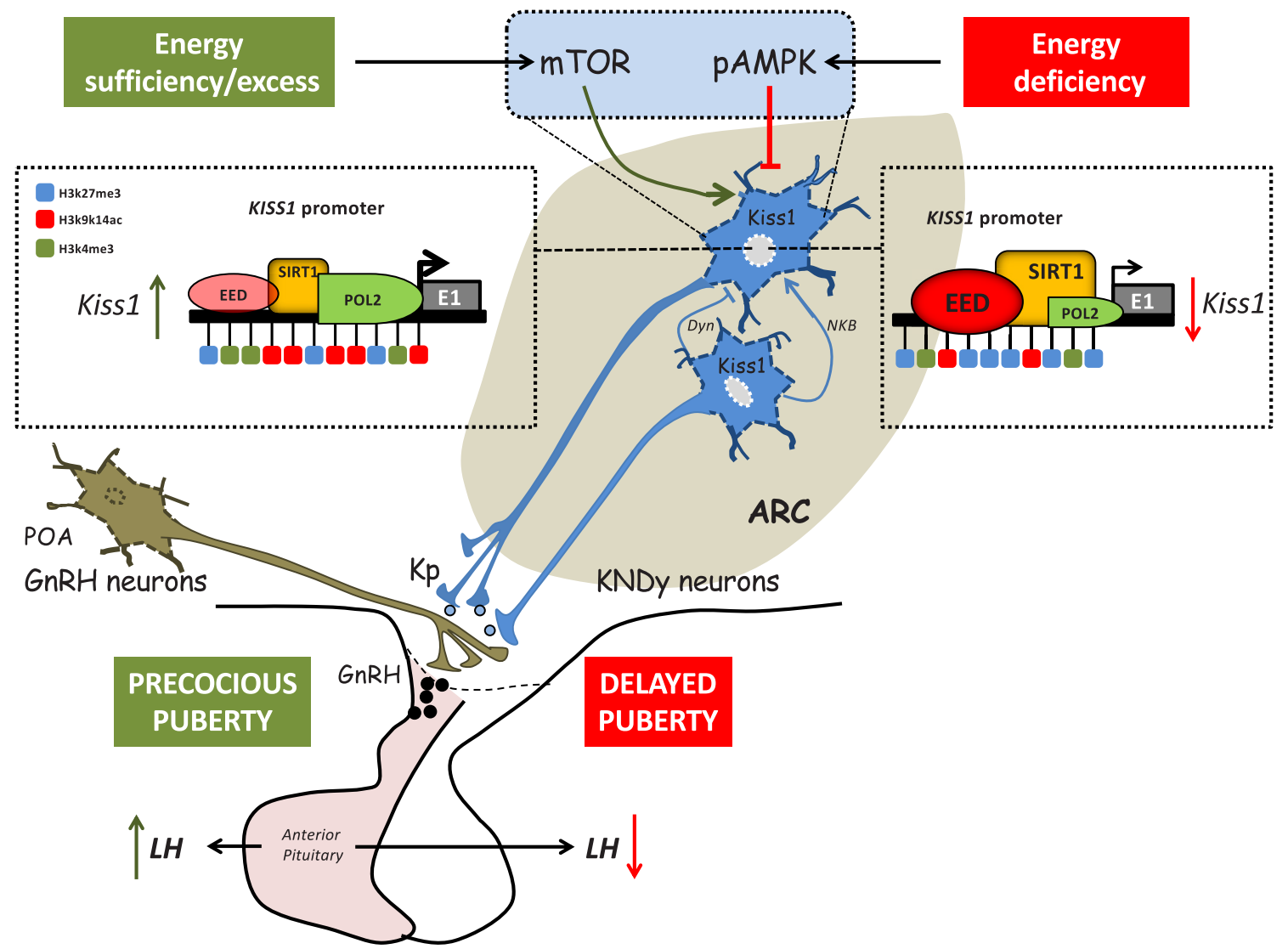

\section{Figure 1}

Contribution of the energy/metabolic sensors, mTOR, AMPK and SIRT1, to the central control of puberty and its alterations in conditions of energy excess or deficiency. A model is presented, based on preclinical (rodent) studies, on the putative function of mTOR and AMPK, as reciprocal activator and inhibitor of ARC Kiss1 neurons (also named KNDy due to the co-expression of NKB and Dynorphin). The balance of the mTOR/AMPK tandem is driven by the state of energy reserves: in conditions of energy sufficiency or excess, activation of mTOR predominates, whereas in situations of energy deficiency, AMPK becomes activated while mTOR is inhibited. The latter conditions (AMPK activation/mTOR inhibition) lead to suppressed Kiss1 and delayed puberty. In addition, changes in SIRT1 content/activity in ARC Kiss1 neurons participate also in the metabolic/nutritional control of Kiss1 transcription. In conditions of energy excess, SIRT1 is partially evicted, together with the repressor, EED, from the Kiss1 promoter (denoted by smaller symbol), which allows enhancement of Kiss1 expression. Conversely, in conditions of energy insufficiency, the Kiss1/EED duo remains at high levels at the Kiss1 promoter, locking a repressive configuration of the chromatin landscape that suppresses Kiss1 expression. Changes in Kiss1 expression/activity translate into changes in the kisspeptin output onto the terminals of GnRH neurons, whose release of GnRH into the portal circuit controls pituitary gonadotropin (in the scheme, LH) secretion, as major driving force for gonadal maturation and puberty onset. For further details, see 'Cellular energy sensors and the metabolic control of puberty: roles of mTOR and AMPK' and 'Linking puberty and longevity? Emerging roles of Sirtuin-1 in the metabolic control of puberty' sections. 
mTOR/AMPK system, causing an inhibition of mTOR and the activation of AMPK signaling, the latter presumably in ARC Kiss1 neurons. Such a switch in the mTOR/AMPK balance would be prone to suppression of Kiss1 expression and, thereby, may contribute to defer pubertal timing in conditions of energy deficit. In addition, the protracted repressive action at the Kiss1 promoter of SIRT1, whose levels are enhanced in ARC Kiss1 neurons in conditions of subnutrition, would lock the chromatin landscape of this promoter into a repressive configuration, reminiscent of that seen in prepubertal stages, therefore adding to the inhibitory influence of the changes in mTOR and AMPK activity indicated above. Identification of such a novel molecular hub for pubertal repression, dominated by AMPK and SIRT1, may have implications also for the management of pubertal disorders involving advanced puberty, in which deferring puberty onset is a desired outcome. In fact, previous therapies with compounds able to activate AMPK, such as metformin (Foretz et al. 2014), have been shown to delay menarche in girls with higher risk of precocious puberty (Ibanez et al. 2011). Therefore, AMPK (and SIRT1) signaling in Kiss1 neurons in the ARC might be considered a tenable target to defer puberty onset in conditions of risk of precocity, as child obesity.

On the other hand, the central mechanisms whereby early-onset obesity, which causes an elevation of circulating leptin levels, may advance pubertal maturation are likely to involve changes in SIRT1 activity mainly in ARC Kiss1 neurons, in which SIRT1 content decreases in preclinical models of overweight. Thus, the premature eviction of SIRT1 from the Kiss1 promoter in this neuronal population would contribute to an earlier change in the epigenetic landscape in this promoter toward a more permissive configuration, allowing an advance in the increase of Kiss1 expression that occurs during puberty. Such a heightening in Kiss1 would drive an earlier activation of GnRH neurosecretion and, thereby, puberty onset. Admittedly, the contribution of SIRT1 to modulate the tempo of puberty might involve also the epigenetic regulation of Kiss1-related transmitters, such as NKB, albeit the participation of SIRT1 in the control of NKB expression by nutritional cues appears to be modest. Likewise, we cannot exclude the potential contribution of changes in the mTOR/AMPK tandem in the pathogenesis of altered puberty linked to obesity; for example, based on our preclinical data, a heightening of central mTOR signaling driven by elevated leptin levels would favor an earlier puberty onset in conditions of overweight. However, the actual role of these cellular energy sensors in obesity-induced pubertal alterations is yet to be defined.

\section{Conclusions}

Puberty is a fascinating developmental phenomenon with long-term consequences, not only on reproductive function, but also on a wide range of body systems, from growth and metabolic control to psychological maturation. Accordingly, perturbations in the age of puberty can be considered as a putative risk factor for a number of pathologies later in life; a feature that urges for a better comprehension of the physiological basis of puberty and the pathophysiological mechanisms of its alterations. Given the prominent influence of nutritional cues and metabolic signals on the control of puberty, both in normal and pathological conditions, complete unraveling of the precise pathways and molecular mechanisms whereby body energy status and metabolic homeostasis (or its lack of) influence puberty appears mandatory not only science-wise but also medicinewise, as such knowledge should set the grounds for better understanding and management of a substantial fraction of pubertal disorders in the near future.

\section{Declaration of interest}

The authors declare that there is no conflict of interest that could be perceived as prejudicing the impartiality of this review.

\section{Funding}

This work did not receive any specific grant from any funding agency in the public, commercial, or not-for-profit sector.

\section{Acknowledgements}

The authors are indebted with the members of their research team at the Physiology Section of the University of Cordoba and IMIBIC, who actively participated in the generation of some experimental data discussed herein. The work from the authors' laboratory summarized in this article was supported by grants BFU2014-57581-P and BFU201783934-P (Ministerio de Economía y Competitividad, Spain; co-funded with EU funds from FEDER Program); project PIE14-00005 (Flexi-Met, Instituto de Salud Carlos III, Ministerio de Sanidad, Spain); Projects P08-CVI-03788 and P12-FQM-01943 (Junta de Andalucía, Spain); and EU research contract DEER FP7-ENV-2007-1. CIBER is an initiative of Instituto de Salud Carlos III (Ministerio de Sanidad, Spain).

\section{References}

Adekunbi DA, Li XF, Li S, Adegoke OA, Iranloye BO, Morakinyo AO, Lightman SL, Taylor PD, Poston L \& O’Byrne KT 2017 Role of amygdala kisspeptin in pubertal timing in female rats. PLOS ONE 12 e0183596. (https://doi.org/10.1371/journal.pone.0183596) 
Ahima RS, Saper CB, Flier JS \& Elmquist JK 2000 Leptin regulation of neuroendocrine systems. Frontiers in Neuroendocrinology 21 263-307. (https://doi.org/10.1006/frne.2000.0197)

Aksglaede L, Juul A, Olsen LW \& Sorensen TI 2009a Age at puberty and the emerging obesity epidemic. PLOS ONE 4 e8450. (https://doi. org/10.1371/journal.pone.0008450)

Aksglaede L, Sorensen K, Petersen JH, Skakkebaek NE \& Juul A $2009 b$ Recent decline in age at breast development: the Copenhagen Puberty Study. Pediatrics 123 e932-e939. (https://doi.org/10.1542/peds.20082491)

Avendano MS, Vazquez MJ \& Tena-Sempere M 2017 Disentangling puberty: novel neuroendocrine pathways and mechanisms for the control of mammalian puberty. Human Reproduction Update 23 737-763. (https://doi.org/10.1093/humupd/dmx025)

Backholer K, Smith JT, Rao A, Pereira A, Iqbal J, Ogawa S, Li Q \& Clarke IJ 2010 Kisspeptin cells in the ewe brain respond to leptin and communicate with neuropeptide $\mathrm{Y}$ and proopiomelanocortin cells. Endocrinology 151 2233-2243. (https://doi.org/10.1210/en.2009-1190)

Bellefontaine N, Chachlaki K, Parkash J, Vanacker C, Colledge W, d'Anglemont de Tassigny X, Garthwaite J, Bouret SG \& Prevot V 2014 Leptin-dependent neuronal NO signaling in the preoptic hypothalamus facilitates reproduction. Journal of Clinical Investigation 124 2550-2559. (https://doi.org/10.1172/JCI65928)

Bentsen AH, Ansel L, Simonneaux V, Tena-Sempere M, Juul A \& Mikkelsen JD 2010 Maturation of kisspeptinergic neurons coincides with puberty onset in male rats. Peptides 31 275-283. (https://doi. org/10.1016/j.peptides.2009.11.017)

Canto C, Gerhart-Hines Z, Feige JN, Lagouge M, Noriega L, Milne JC, Elliott PJ, Puigserver P \& Auwerx J 2009 AMPK regulates energy expenditure by modulating $\mathrm{NAD}^{+}$metabolism and SIRT1 activity. Nature 458 1056-1060. (https://doi.org/10.1038/nature07813)

Castellano JM \& Tena-Sempere M 2016 Metabolic control of female puberty: potential therapeutic targets. Expert Opinion on Therapeutic Targets 20 1181-1193. (https://doi.org/10.1080/14728222.2016.121 2015)

Castellano JM, Navarro VM, Fernandez-Fernandez R, Nogueiras R, Tovar S, Roa J, Vazquez MJ, Vigo E, Casanueva FF, Aguilar E, et al. 2005 Changes in hypothalamic KiSS-1 system and restoration of pubertal activation of the reproductive axis by kisspeptin in undernutrition. Endocrinology 146 3917-3925. (https://doi. org/10.1210/en.2005-0337)

Castellano JM, Navarro VM, Fernandez-Fernandez R, Castano JP, Malagon MM, Aguilar E, Dieguez C, Magni P, Pinilla L \& TenaSempere M 2006 Ontogeny and mechanisms of action for the stimulatory effect of kisspeptin on gonadotropin-releasing hormone system of the rat. Molecular and Cellular Endocrinology 257-258 75-83. (https://doi.org/10.1016/j.mce.2006.07.002)

Castellano JM, Bentsen AH, Sanchez-Garrido MA, Ruiz-Pino F, Romero M, Garcia-Galiano D, Aguilar E, Pinilla L, Dieguez C, Mikkelsen JD, et al. 2011 Early metabolic programming of puberty onset: impact of changes in postnatal feeding and rearing conditions on the timing of puberty and development of the hypothalamic kisspeptin system. Endocrinology 152 3396-3408. (https://doi.org/10.1210/en.2010-1415)

Chang HC \& Guarente L 2014 SIRT1 and other sirtuins in metabolism. Trends in Endocrinology and Metabolism 25 138-145. (https://doi. org/10.1016/j.tem.2013.12.001)

Clarkson J \& Herbison AE 2006 Postnatal development of kisspeptin neurons in mouse hypothalamus; sexual dimorphism and projections to gonadotropin-releasing hormone neurons. Endocrinology 147 5817-5825. (https://doi.org/10.1210/en.2006-0787)

Cota D, Proulx K, Smith KA, Kozma SC, Thomas G, Woods SC \& Seeley RJ 2006 Hypothalamic mTOR signaling regulates food intake. Science 312 927-930. (https://doi.org/10.1126/science.1124147)

Coyral-Castel S, Tosca L, Ferreira G, Jeanpierre E, Rame C, Lomet D, Caraty A, Monget P, Chabrolle C \& Dupont J 2008 The effect of AMP-activated kinase activation on gonadotrophin-releasing hormone secretion in GT1-7 cells and its potential role in hypothalamic regulation of the oestrous cyclicity in rats. Journal of Neuroendocrinology 20 335-346. (https://doi.org/10.1111/j.13652826.2007.01643.x)

Cravo RM, Margatho LO, Osborne-Lawrence S, Donato Jr J, Atkin S, Bookout AL, Rovinsky S, Frazao R, Lee CE, Gautron L, et al. 2011 Characterization of Kiss1 neurons using transgenic mouse models. Neuroscience 173 37-56. (https://doi.org/10.1016/j. neuroscience.2010.11.022)

Cravo RM, Frazao R, Perello M, Osborne-Lawrence S, Williams KW, Zigman JM, Vianna C \& Elias CF 2013 Leptin signaling in Kiss1 neurons arises after pubertal development. PLOS ONE $\mathbf{8}$ e58698. (https://doi.org/10.1371/journal.pone.0058698)

Croizier S, Park S, Maillard J \& Bouret SG 2018 Central DicermiR-103/107 controls developmental switch of POMC progenitors into NPY neurons and impacts glucose homeostasis. eLife 7 e40429. (https://doi.org/10.7554/eLife.40429)

d'Anglemont de Tassigny X, Fagg LA, Dixon JP, Day K, Leitch HG, Hendrick AG, Zahn D, Franceschini I, Caraty A, Carlton MB, et al. 2007 Hypogonadotropic hypogonadism in mice lacking a functional Kiss1 gene. PNAS 104 10714-10719. (https://doi.org/10.1073/ pnas.0704114104)

Day FR, Elks CE, Murray A, Ong KK \& Perry JR 2015 Puberty timing associated with diabetes, cardiovascular disease and also diverse health outcomes in men and women: the UK biobank study. Scientific Reports 5 11208. (https://doi.org/10.1038/srep11208)

De Leonibus C, Marcovecchio ML, Chiavaroli V, de Giorgis T, Chiarelli F \& Mohn A 2014 Timing of puberty and physical growth in obese children: a longitudinal study in boys and girls. Pediatric Obesity 9 292-299. (https://doi.org/10.1111/j.2047-6310.2013.00176.x)

de Roux N, Genin E, Carel JC, Matsuda F, Chaussain JL \& Milgrom E 2003 Hypogonadotropic hypogonadism due to loss of function of the KiSS1-derived peptide receptor GPR54. PNAS 100 10972-10976. (https://doi.org/10.1073/pnas.1834399100)

Di Sante G, Wang L, Wang C, Jiao X, Casimiro MC, Chen K, Pestell TG, Yaman I, Di Rocco A, Sun X, et al. 2015 Sirt1-deficient mice have hypogonadotropic hypogonadism due to defective GnRH neuronal migration. Molecular Endocrinology 29 200-212. (https://doi. org/10.1210/me.2014-1228)

Donato Jr J, Cravo RM, Frazao R \& Elias CF 2011a Hypothalamic sites of leptin action linking metabolism and reproduction. Neuroendocrinology 93 9-18. (https://doi.org/10.1159/000322472)

Donato Jr J, Cravo RM, Frazao R, Gautron L, Scott MM, Lachey J, Castro IA, Margatho LO, Lee S, Lee C, et al. $2011 b$ Leptin's effect on puberty in mice is relayed by the ventral premammillary nucleus and does not require signaling in Kiss1 neurons. Journal of Clinical Investigation 121 355-368. (https://doi.org/10.1172/JCI45106)

Donato Jr J, Lee C, Ratra DV, Franci CR, Canteras NS \& Elias CF 2013 Lesions of the ventral premammillary nucleus disrupt the dynamic changes in Kiss1 and GnRH expression characteristic of the proestrusestrus transition. Neuroscience 241 67-79. (https://doi.org/10.1016/j. neuroscience.2013.03.013)

Elias CF 2012 Leptin action in pubertal development: recent advances and unanswered questions. Trends in Endocrinology and Metabolism 23 9-15. (https://doi.org/10.1016/j.tem.2011.09.002)

Farooqi IS \& O'Rahilly S 201420 years of leptin: human disorders of leptin action. Journal of Endocrinology 223 T63-T70. (https://doi. org/10.1530/JOE-14-0480)

Fergani C, Leon S, Padilla SL, Verstegen AM, Palmiter RD \& Navarro VM 2018 NKB signaling in the posterodorsal medial amygdala stimulates gonadotropin release in a kisspeptin-independent manner in female mice. eLife 7 e40476. (https://doi.org/10.7554/eLife.40476)

Finn PD, Cunningham MJ, Pau KY, Spies HG, Clifton DK \& Steiner RA 1998 The stimulatory effect of leptin on the neuroendocrine reproductive axis of the monkey. Endocrinology $1394652-4662$. (https://doi.org/10.1210/endo.139.11.6297) https://joe.bioscientifica.com https://doi.org/10.1530/JOE-19-0223 (c) 2019 Society for Endocrinology Published by Bioscientifica Ltd. Printed in Great Britain 
Foretz M, Guigas B, Bertrand L, Pollak M \& Viollet B 2014 Metformin: from mechanisms of action to therapies. Cell Metabolism 20 953-966. (https://doi.org/10.1016/j.cmet.2014.09.018)

Frisch RE \& Revelle R 1970 Height and weight at menarche and a hypothesis of critical body weights and adolescent events. Science 169 397-399. (https://doi.org/10.1126/science.169.3943.397)

Giacobini P, Parkash J, Campagne C, Messina A, Casoni F, Vanacker C, Langlet F, Hobo B, Cagnoni G, Gallet S, et al. 2014 Brain endothelial cells control fertility through ovarian-steroid-dependent release of semaphorin 3A. PLoS Biology 12 e1001808. (https://doi.org/10.1371/ journal.pbio.1001808)

Giblin W, Skinner ME \& Lombard DB 2014 Sirtuins: guardians of mammalian healthspan. Trends in Genetics 30 271-286. (https://doi. org/10.1016/j.tig.2014.04.007)

Gill JC, Navarro VM, Kwong C, Noel SD, Martin C, Xu S, Clifton DK, Carroll RS, Steiner RA \& Kaiser UB 2012 Increased neurokinin B (Tac2) expression in the mouse arcuate nucleus is an early marker of pubertal onset with differential sensitivity to sex steroid-negative feedback than Kiss1. Endocrinology 153 4883-4893. (https://doi. org/10.1210/en.2012-1529)

Guerriero KA, Keen KL, Millar RP \& Terasawa E 2012 Developmental changes in GnRH release in response to kisspeptin agonist and antagonist in female rhesus monkeys (Macaca mulatta): implication for the mechanism of puberty. Endocrinology 153 825-836. (https:// doi.org/10.1210/en.2011-1565)

Hanchate NK, Giacobini P, Lhuillier P, Parkash J, Espy C, Fouveaut C, Leroy C, Baron S, Campagne C, Vanacker C, et al. 2012 SEMA3A, a gene involved in axonal pathfinding, is mutated in patients with Kallmann syndrome. PLoS Genetics 8 e1002896. (https://doi. org/10.1371/journal.pgen.1002896)

Hardie DG, Ross FA \& Hawley SA 2012 AMPK: a nutrient and energy sensor that maintains energy homeostasis. Nature Reviews: Molecular Cell Biology 13 251-262. (https://doi.org/10.1038/nrm3311)

Herbison AE 2016 Control of puberty onset and fertility by gonadotropinreleasing hormone neurons. Nature Reviews: Endocrinology 12 452-466. (https://doi.org/10.1038/nrendo.2016.70)

Herman-Giddens ME, Steffes J, Harris D, Slora E, Hussey M, Dowshen SA, Wasserman R, Serwint JR, Smitherman L \& Reiter EO 2012 Secondary sexual characteristics in boys: data from the Pediatric Research in Office Settings Network. Pediatrics 130 e1058-e1068. (https://doi. org/10.1542/peds.2011-3291)

Hill JW \& Elias CF 2018 Neuroanatomical framework of the metabolic control of reproduction. Physiological Reviews 98 2349-2380. (https:// doi.org/10.1152/physrev.00033.2017)

Ibanez L, Lopez-Bermejo A, Diaz M, Marcos MV \& de Zegher F 2011 Early metformin therapy to delay menarche and augment height in girls with precocious pubarche. Fertility and Sterility 95 727-730. (https:// doi.org/10.1016/j.fertnstert.2010.08.052)

Knobil E 1980 The neuroendocrine control of the menstrual cycle. Recent Progress in Hormone Research 36 53-88.

Kolthur-Seetharam U, Teerds K, de Rooij DG, Wendling O, McBurney M, Sassone-Corsi P \& Davidson I 2009 The histone deacetylase SIRT1 controls male fertility in mice through regulation of hypothalamicpituitary gonadotropin signaling. Biology of Reproduction 80 384-391. (https://doi.org/10.1095/biolreprod.108.070193)

Lakshman R, Forouhi NG, Sharp SJ, Luben R, Bingham SA, Khaw KT, Wareham NJ \& Ong KK 2009 Early age at menarche associated with cardiovascular disease and mortality. Journal of Clinical Endocrinology and Metabolism 94 4953-4960. (https://doi.org/10.1210/jc.2009. 1789)

Lehman MN, Coolen LM \& Goodman RL 2010 Minireview: kisspeptin/ neurokinin B/dynorphin (KNDy) cells of the arcuate nucleus: a central node in the control of gonadotropin-releasing hormone secretion. Endocrinology 151 3479-3489. (https://doi.org/10.1210/ en.2010-0022)
Lomniczi A \& Ojeda SR 2016 The emerging role of epigenetics in the regulation of female puberty. Endocrine Development 29 1-16. (https:// doi.org/10.1159/000438840)

Lomniczi A, Wright H \& Ojeda SR 2015 Epigenetic regulation of female puberty. Frontiers in Neuroendocrinology 36 90-107. (https://doi. org/10.1016/j.yfrne.2014.08.003)

Lopez M, Nogueiras R, Tena-Sempere M \& Dieguez C 2016 Hypothalamic AMPK: a canonical regulator of whole-body energy balance. Nature Reviews: Endocrinology 12 421-432. (https://doi.org/10.1038/ nrendo.2016.67)

Louis GW, Greenwald-Yarnell M, Phillips R, Coolen LM, Lehman MN \& Myers Jr MG 2011 Molecular mapping of the neural pathways linking leptin to the neuroendocrine reproductive axis. Endocrinology 152 2302-2310. (https://doi.org/10.1210/en.2011-0096)

Louis GW \& Myers Jr MG 2007 The role of leptin in the regulation of neuroendocrine function and CNS development. Reviews in Endocrine and Metabolic Disorders 8 85-94. (https://doi.org/10.1007/s11154-0079043-3)

Maeda K, Ohkura S, Uenoyama Y, Wakabayashi Y, Oka Y, Tsukamura H \& Okamura H 2010 Neurobiological mechanisms underlying GnRH pulse generation by the hypothalamus. Brain Research 1364 103-115. (https://doi.org/10.1016/j.brainres.2010.10.026)

Manfredi-Lozano M, Roa J, Ruiz-Pino F, Piet R, Garcia-Galiano D, Pineda R, Zamora A, Leon S, Sanchez-Garrido MA, Romero-Ruiz A, et al. 2016 Defining a novel leptin-melanocortin-kisspeptin pathway involved in the metabolic control of puberty. Molecular Metabolism $\mathbf{5}$ 844-857. (https://doi.org/10.1016/j.molmet.2016.08.003)

Manfredi-Lozano M, Roa J \& Tena-Sempere M 2018 Connecting metabolism and gonadal function: novel central neuropeptide pathways involved in the metabolic control of puberty and fertility. Frontiers in Neuroendocrinology 48 37-49. (https://doi.org/10.1016/j. yfrne.2017.07.008)

Marcos S, Monnier C, Rovira X, Fouveaut C, Pitteloud N, Ango F, Dode C \& Hardelin JP 2017 Defective signaling through plexin-A1 compromises the development of the peripheral olfactory system and neuroendocrine reproductive axis in mice. Human Molecular Genetics 26 2006-2017. (https://doi.org/10.1093/hmg/ddx080)

Martin C, Navarro VM, Simavli S, Vong L, Carroll RS, Lowell BB \& Kaiser UB 2014 Leptin-responsive GABAergic neurons regulate fertility through pathways that result in reduced kisspeptinergic tone. Journal of Neuroscience 34 6047-6056. (https://doi.org/10.1523/ JNEUROSCI.3003-13.2014)

Martins L, Fernandez-Mallo D, Novelle MG, Vázquez MJ, TenaSempere M, Nogueiras R, López M \& Diéguez C, Vazquez MJ, Lopez M \& Dieguez C 2012 Hypothalamic mTOR signaling mediates the orexigenic action of ghrelin. PLOS ONE 7 e46923. (https://doi. org/10.1371/journal.pone.0046923)

McBurney MW, Yang X, Jardine K, Hixon M, Boekelheide K, Webb JR, Lansdorp PM \& Lemieux M 2003 The mammalian SIR2alpha protein has a role in embryogenesis and gametogenesis. Molecular and Cellular Biology 23 38-54. (https://doi.org/10.1128/mcb.23.1.38-54.2003)

Messina A, Langlet F, Chachlaki K, Roa J, Rasika S, Jouy N, Gallet S, Gaytan F, Parkash J, Tena-Sempere M, et al. 2016 A microRNA switch regulates the rise in hypothalamic GnRH production before puberty. Nature Neuroscience 19 835-844. (https://doi.org/10.1038/nn.4298)

Minabe S, Deura C, Ikegami K, Goto T, Sanbo M, Hirabayashi M, Inoue N, Uenoyama Y, Maeda K \& Tsukamura H 2015 Pharmacological and morphological evidence of AMPK-mediated energy sensing in the lower brain stem ependymocytes to control reproduction in female rodents. Endocrinology 156 2278-2287. (https://doi.org/10.1210/ en.2014-2018)

Nakahara T, Uenoyama Y, Iwase A, Oishi S, Nakamura S, Minabe S, Watanabe Y, Deura C, Noguchi T, Fujii N, et al. 2013 Chronic peripheral administration of kappa-opioid receptor antagonist advances puberty onset associated with acceleration of pulsatile https://joe.bioscientifica.com https://doi.org/10.1530/JOE-19-0223 (c) 2019 Society for Endocrinology Published by Bioscientifica Ltd. Printed in Great Britain 
luteinizing hormone secretion in female rats. Journal of Reproduction and Development 59 479-484. (https://doi.org/10.1262/jrd.2013-046)

Navarro VM 2013 Interactions between kisspeptins and neurokinin B. Advances in Experimental Medicine and Biology 784 325-347. (https:// doi.org/10.1007/978-1-4614-6199-9_15)

Navarro VM \& Tena-Sempere M 2011 Neuroendocrine control by kisspeptins: role in metabolic regulation of fertility. Nature Reviews: Endocrinology 8 40-53. (https://doi.org/10.1038/nrendo.2011.147)

Navarro VM, Castellano JM, Fernandez-Fernandez R, Barreiro ML, Roa J, Sanchez-Criado JE, Aguilar E, Dieguez C, Pinilla L \& Tena-Sempere M $2004 a$ Developmental and hormonally regulated messenger ribonucleic acid expression of KiSS-1 and its putative receptor, GPR54, in rat hypothalamus and potent luteinizing hormone-releasing activity of KiSS-1 peptide. Endocrinology 145 4565-4574. (https://doi org/10.1210/en.2004-0413)

Navarro VM, Fernandez-Fernandez R, Castellano JM, Roa J, Mayen A, Barreiro ML, Gaytan F, Aguilar E, Pinilla L, Dieguez C, et al. 2004b Advanced vaginal opening and precocious activation of the reproductive axis by KiSS-1 peptide, the endogenous ligand of GPR54. Journal of Physiology 561 379-386. (https://doi.org/10.1113/ jphysiol.2004.072298)

Navarro VM, Gottsch ML, Chavkin C, Okamura H, Clifton DK \& Steiner RA 2009 Regulation of gonadotropin-releasing hormone secretion by kisspeptin/dynorphin/neurokinin B neurons in the arcuate nucleus of the mouse. Journal of Neuroscience 29 11859-11866. (https://doi.org/10.1523/JNEUROSCI.1569-09.2009)

Navarro VM, Ruiz-Pino F, Sanchez-Garrido MA, Garcia-Galiano D, Hobbs SJ, Manfredi-Lozano M, Leon S, Sangiao-Alvarellos S, Castellano JM, Clifton DK, et al. 2012 Role of neurokinin B in the control of female puberty and its modulation by metabolic status. Journal of Neuroscience 32 2388-2397. (https://doi.org/10.1523/ JNEUROSCI.4288-11.2012)

Nogueiras R, Habegger KM, Chaudhary N, Finan B, Banks AS, Dietrich MO, Horvath TL, Sinclair DA, Pfluger PT \& Tschop MH 2012 Sirtuin 1 and sirtuin 3: physiological modulators of metabolism. Physiological Reviews 92 1479-1514. (https://doi.org/10.1152/ physrev.00022.2011)

Ojeda SR, Lomniczi A \& Sandau U 2010 Contribution of glial-neuronal interactions to the neuroendocrine control of female puberty. European Journal of Neuroscience 32 2003-2010. (https://doi. org/10.1111/j.1460-9568.2010.07515.x)

Pineda R, Garcia-Galiano D, Roseweir A, Romero M, Sanchez-Garrido MA, Ruiz-Pino F, Morgan K, Pinilla L, Millar RP \& Tena-Sempere M 2010 Critical roles of kisspeptins in female puberty and preovulatory gonadotropin surges as revealed by a novel antagonist. Endocrinology 151 722-730. (https://doi.org/10.1210/en.2009-0803)

Pineda R, Plaisier F, Millar RP \& Ludwig M 2017 Amygdala kisspeptin neurons: putative mediators of olfactory control of the gonadotropic axis. Neuroendocrinology 104 223-238. (https://doi. org/10.1159/000445895)

Pinilla L, Aguilar E, Dieguez C, Millar RP \& Tena-Sempere M 2012 Kisspeptins and reproduction: physiological roles and regulatory mechanisms. Physiological Reviews 92 1235-1316. (https://doi. org/10.1152/physrev.00037.2010)

Prevot V, Dehouck B, Sharif A, Ciofi P, Giacobini P \& Clasadonte J 2018 The versatile tanycyte: a hypothalamic integrator of reproduction and energy metabolism. Endocrine Reviews 39 333-368. (https://doi. org/10.1210/er.2017-00235)

Qiu J, Fang Y, Bosch MA, Ronnekleiv OK \& Kelly MJ 2011 Guinea pig kisspeptin neurons are depolarized by leptin via activation of TRPC channels. Endocrinology 152 1503-1514. (https://doi.org/10.1210/ en.2010-1285)

Quennell JH, Mulligan AC, Tups A, Liu X, Phipps SJ, Kemp CJ, Herbison AE, Grattan DR \& Anderson GM 2009 Leptin indirectly regulates gonadotropin-releasing hormone neuronal function. Endocrinology 150 2805-2812. (https://doi.org/10.1210/en.2008-1693)
Quennell JH, Howell CS, Roa J, Augustine RA, Grattan DR \& Anderson GM 2011 Leptin deficiency and diet-induced obesity reduce hypothalamic kisspeptin expression in mice. Endocrinology 152 1541-1550. (https://doi.org/10.1210/en.2010-1100)

Ramadori G, Lee CE, Bookout AL, Lee S, Williams KW, Anderson J, Elmquist JK \& Coppari R 2008 Brain SIRT1: anatomical distribution and regulation by energy availability. Journal of Neuroscience $\mathbf{2 8}$ 9989-9996. (https://doi.org/10.1523/JNEUROSCI.3257-08.2008)

Roa J \& Tena-Sempere M 2010 Energy balance and puberty onset: emerging role of central mTOR signaling. Trends in Endocrinology and Metabolism 21 519-528. (https://doi.org/10.1016/j.tem.2010.05.003)

Roa J, Vigo E, Garcia-Galiano D, Castellano JM, Navarro VM, Pineda R, Dieguez C, Aguilar E, Pinilla L \& Tena-Sempere M 2008 Desensitization of gonadotropin responses to kisspeptin in the female rat: analyses of LH and FSH secretion at different developmental and metabolic states. American Journal of Physiology: Endocrinology and Metabolism 294 E1088-E1096. (https://doi.org/10.1152/ ajpendo.90240.2008)

Roa J, Garcia-Galiano D, Varela L, Sanchez-Garrido MA, Pineda R, Castellano JM, Ruiz-Pino F, Romero M, Aguilar E, Lopez M, et al. 2009 The mammalian target of rapamycin as novel central regulator of puberty onset via modulation of hypothalamic Kiss1 system. Endocrinology 150 5016-5026. (https://doi.org/10.1210/en.2009-0096)

Roa J, Barroso A, Ruiz-Pino F, Vazquez MJ, Seoane-Collazo P, MartinezSanchez N, Garcia-Galiano D, Ilhan T, Pineda R, Leon S, et al. 2018 Metabolic regulation of female puberty via hypothalamic AMPKkisspeptin signaling. PNAS 115 E10758-E10767. (https://doi. org/10.1073/pnas.1802053115)

Roland AV \& Moenter SM 2011 Regulation of gonadotropin-releasing hormone neurons by glucose. Trends in Endocrinology and Metabolism 22 443-449. (https://doi.org/10.1016/j.tem.2011.07.001)

Ross RA, Leon S, Madara JC, Schafer D, Fergani C, Maguire CA, Verstegen AM, Brengle E, Kong D, Herbison AE, et al. 2018 PACAP neurons in the ventral premammillary nucleus regulate reproductive function in the female mouse. eLife 7 e35960. (https://doi. org/10.7554/eLife.35960)

Sanchez-Garrido MA, Castellano JM, Ruiz-Pino F, Garcia-Galiano D, Manfredi-Lozano M, Leon S, Romero-Ruiz A, Dieguez C, Pinilla L \& Tena-Sempere M 2013 Metabolic programming of puberty: sexually dimorphic responses to early nutritional challenges. Endocrinology 154 3387-3400. (https://doi.org/10.1210/en.2012-2157)

Sanchez-Garrido MA, Ruiz-Pino F, Manfredi-Lozano M, Leon S, GarciaGaliano D, Castano JP, Luque RM, Romero-Ruiz A, Castellano JM, Dieguez C, et al. 2014 Obesity-induced hypogonadism in the male: premature reproductive neuroendocrine senescence and contribution of Kiss1-mediated mechanisms. Endocrinology 155 1067-1079. (https://doi.org/10.1210/en.2013-1584)

Seminara SB, Messager S, Chatzidaki EE, Thresher RR, Acierno Jr JS, Shagoury JK, Bo-Abbas Y, Kuohung W, Schwinof KM, Hendrick AG, et al. 2003 The GPR54 gene as a regulator of puberty. New England Journal of Medicine 349 1614-1627. (https://doi.org/10.1056/ NEJMoa035322)

Shahab M, Mastronardi C, Seminara SB, Crowley WF, Ojeda SR \& Plant TM 2005 Increased hypothalamic GPR54 signaling: a potential mechanism for initiation of puberty in primates. PNAS 102 2129-2134. (https://doi.org/10.1073/pnas.0409822102)

Simavli S, Thompson IR, Maguire CA, Gill JC, Carroll RS, Wolfe A, Kaiser UB \& Navarro VM 2015 Substance P regulates puberty onset and fertility in the female mouse. Endocrinology 156 2313-2322. (https://doi.org/10.1210/en.2014-2012)

Smith JT, Acohido BV, Clifton DK \& Steiner RA 2006 KiSS-1 neurones are direct targets for leptin in the ob/ob mouse. Journal of Neuroendocrinology 18 298-303. (https://doi.org/10.1111/j.13652826.2006.01417.x)

Stephens SB, Chahal N, Munaganuru N, Parra RA \& Kauffman AS 2016 Estrogen stimulation of Kiss1 expression in the medial amygdala https://joe.bioscientifica.com https://doi.org/10.1530/JOE-19-0223 (c) 2019 Society for Endocrinology Published by Bioscientifica Ltd. Printed in Great Britain 
involves estrogen receptor- $\alpha$ but not estrogen receptor- $\beta$. Endocrinology 157 4021-4031. (https://doi.org/10.1210/en.2016-1431)

Tatone C, Di Emidio G, Barbonetti A, Carta G, Luciano AM, Falone S \& Amicarelli F 2018 Sirtuins in gamete biology and reproductive physiology: emerging roles and therapeutic potential in female and male infertility. Human Reproduction Update 24 267-289. (https://doi. org/10.1093/humupd/dmy003)

Tena-Sempere M \& Huhtaniemi I 2003 Gonadotropins and gonadotropin receptors. In Reproductive Medicine - Molecular, Cellular and Genetic Fundamentals, pp 225-244. Ed BCJM Fauser. New York, NY, USA: Parthenon Publishing.

Topaloglu AK, Reimann F, Guclu M, Yalin AS, Kotan LD, Porter KM, Serin A, Mungan NO, Cook JR, Imamoglu S, et al. 2009 TAC3 and TACR3 mutations in familial hypogonadotropic hypogonadism reveal a key role for neurokinin B in the central control of reproduction. Nature Genetics 41 354-358. (https://doi.org/10.1038/ng.306)

Topaloglu AK, Tello JA, Kotan LD, Ozbek MN, Yilmaz MB, Erdogan S, Gurbuz F, Temiz F, Millar RP \& Yuksel B 2012 Inactivating KISS1 mutation and hypogonadotropic hypogonadism. New England Journal of Medicine 366 629-635. (https://doi.org/10.1056/NEJMoa1111184)

van der Klaauw AA, Croizier S, Mendes de Oliveira E, Stadler LKJ, Park S, Kong Y, Banton MC, Tandon P, Hendricks AE, Keogh JM, et al. 2019
Human semaphorin 3 variants link melanocortin circuit development and energy balance. Cell 176 729-742.e18. (https://doi.org/10.1016/j. cell.2018.12.009)

Vazquez MJ, Romero-Ruiz A \& Tena-Sempere M 2015 Roles of leptin in reproduction, pregnancy and polycystic ovary syndrome: consensus knowledge and recent developments. Metabolism: Clinical and Experimental 64 79-91. (https://doi.org/10.1016/j. metabol.2014.10.013)

Vazquez MJ, Toro CA, Castellano JM, Ruiz-Pino F, Roa J, Beiroa D, Heras V, Velasco I, Dieguez C, Pinilla L, et al. 2018 SIRT1 mediates obesity- and nutrient-dependent perturbation of pubertal timing by epigenetically controlling Kiss1 expression. Nature Communications 9 4194. (https://doi.org/10.1038/s41467-018-06459-9)

Welt CK, Chan JL, Bullen J, Murphy R, Smith P, DePaoli AM, Karalis A \& Mantzoros CS 2004 Recombinant human leptin in women with hypothalamic amenorrhea. New England Journal of Medicine $\mathbf{3 5 1}$ 987-997. (https://doi.org/10.1056/NEJMoa040388)

Wen JP, Liu C, Bi WK, Hu YT, Chen Q, Huang H, Liang JX, Li LT, Lin LX \& Chen G 2012 Adiponectin inhibits KISS1 gene transcription through AMPK and specificity protein-1 in the hypothalamic GT1-7 neurons. Journal of Endocrinology 214 177-189. (https://doi.org/10.1530/JOE12-0054)

Received in final form 4 June 2019

Accepted 10 June 2019

Accepted Preprint published online 10 June 2019 https://joe.bioscientifica.com https://doi.org/10.1530/JOE-19-0223
(C) 2019 Society for Endocrinology Published by Bioscientifica Ltd.
Printed in Great Britain 